\title{
Economic Abuse Within Intimate Partner Violence: A Review of the Literature
}

\author{
Amanda M. Stylianou, PhD, LCSW \\ Safe Horizon, New York, New York
}

\begin{abstract}
This article reviews the literature on the measurement of, impact of, and interventions for economic abuse within intimate partner relationships. Current assessment measures for economic abuse, along with estimates of the prevalence of economic abuse, are reviewed and critiqued. Research exploring the impact of economic abuse on the victim's mental health and psychological well-being, family formations and parenting practices, and children's behaviors and youth outcomes are presented. Recently developed interventions, including financial literacy program models, are discussed and emphasized as a critical service to increase victims' economic self-efficacy, financial literacy, and financial behaviors. Finally, the review provides detailed recommendations on incorporating economic abuse as a central component of domestic violence research, practice, and policies.
\end{abstract}

Keywords: domestic violence; economic abuse; intimate partner violence; violence against women

I ntimate partner violence (IPV) is a major public health concern. Approximately 1 in 4 women and 1 in 7 men will experience severe violence perpetrated by an intimate partner in their lifetime (Breiding, Chen, \& Black, 2014). Although the definition of IPV varies, the Centers for Disease Control and Prevention (CDC) defines IPV as "physical violence, sexual violence, stalking and psychological aggression by a current or former intimate partner" (CDC, 2016).

The field of IPV has a history of acknowledging both physical and nonphysical forms of abuse (Outlaw, 2009), yet the vast majority of research focuses on the impact of physical forms of IPV. To examine nonphysical forms of abuse, Miller (1995) identified four types of nonphysical abuse including emotional, psychological, social, and economic abuse. According to Miller, emotional abuse involves comments or behaviors intended to undermine the victim's sense of value and self-worth and often includes complaints, insults, name-calling, and public embarrassment. Psychological abuse entails behaviors that the perpetrator uses to degrade the victim's sense of logic and reasoning and involves making the victim feel as if he or she is losing his or her mind (Miller, 1995). Social abuse typically focuses on isolating the victim from his or her family and friends by threat, force, or persuasion (Miller, 1995). Finally, economic abuse centers on creating economic dependency on the perpetrator (Miller, 1995). Among these forms of nonphysical 
abuse, economic abuse has historically been the most understudied form of abuse often being subsumed within emotional or psychological abuse or simply being ignored in the research. This article focuses on providing a comprehensive review of the literature on economic abuse and explores our current understanding of economic abuse, the strengths and weaknesses of current measures and prevalence estimates of economic abuse, and the impact of economic abuse on victims of IPV. In addition, the article provides an overview of interventions designed to target victims experiencing economic abuse and recommends next steps in research, practice, and policy.

\section{ECONOMIC ABUSE: DEFINITION AND TACTICS}

Economic abuse includes behaviors that control a victim's "ability to acquire, use, and maintain resources thus threatening her economic security and potential for self-sufficiency" (Adams, Sullivan, Bybee, \& Greeson, 2008). Similar to forms of psychological abuse (Kasian \& Painter, 1992; Sackett \& Saunders, 1999), economic abuse incorporates behaviors that control both what the victim can and cannot do. Economic abuse occurs when the abuser gains complete control over the victim's financial resources (Fawole, 2008) and includes three forms of economic abuse: economic control, employment sabotage, and economic exploitation (Postmus, Plummer, \& Stylianou, 2015; Stylianou, Postmus, \& McMahon, 2013). See Table 1 for a list of the definitions of and tactics used in economically abusive relationships.

Economic control occurs when the perpetrator prevents the victim from having access to or knowledge of the finances and from having financial decision-making power (Anderson et al., 2003; Brewster, 2003; Postmus, Plummer, et al., 2015). Victims of economic control report their partners control and limit access to financial resources (Sanders, 2015; Wettersten et al., 2004) and deny access to necessities such as food, clothing, and/or medications (Anderson et al., 2003; VonDeLinde, 2002). A perpetrator may track the victim's use of money, withhold or hide jointly earned money, prevent the victim from having access to a bank account, or lie about shared properties and assets (Brewster, 2003; VonDeLinde, 2002).

Employment sabotage encompasses behaviors that prevent the victim from obtaining or maintaining employment (Postmus, Plummer, et al., 2015). Numerous studies document the ways in which perpetrators forbid, discourage, and actively interfere with their partners' employment and/or educational endeavors (Alexander, 2011; Brewster, 2003; Moe \& Bell, 2004; Sanders, 2015; Swanberg \& Logan, 2005; Swanberg \& Macke, 2006; Tolman \& Raphael, 2000; VonDeLinde, 2002; Wettersten et al., 2004). One study, conducted by Riger et al. (2000), examined employment sabotage among 57 primarily African American female victims of domestic violence residing in domestic violence shelters in Chicago. The study found that perpetrators actively interfered with victims' ability to sustain employment by destroying their cars, threatening to physically harm or restrain them, failing to provide child care, stealing their car keys and money, and refusing to provide transportation to work. Similarly, Tolman and Raphael's (2000) review of the literature documented numerous types of employment sabotage including keeping victims up all night with arguments before job interviews, turning off alarm clocks, destroying clothing, inflicting visual facial injuries, disabling the car, threatening to kidnap the children from child care, failing to show up as promised for child care or transportation, and harassing the victim on the job. 


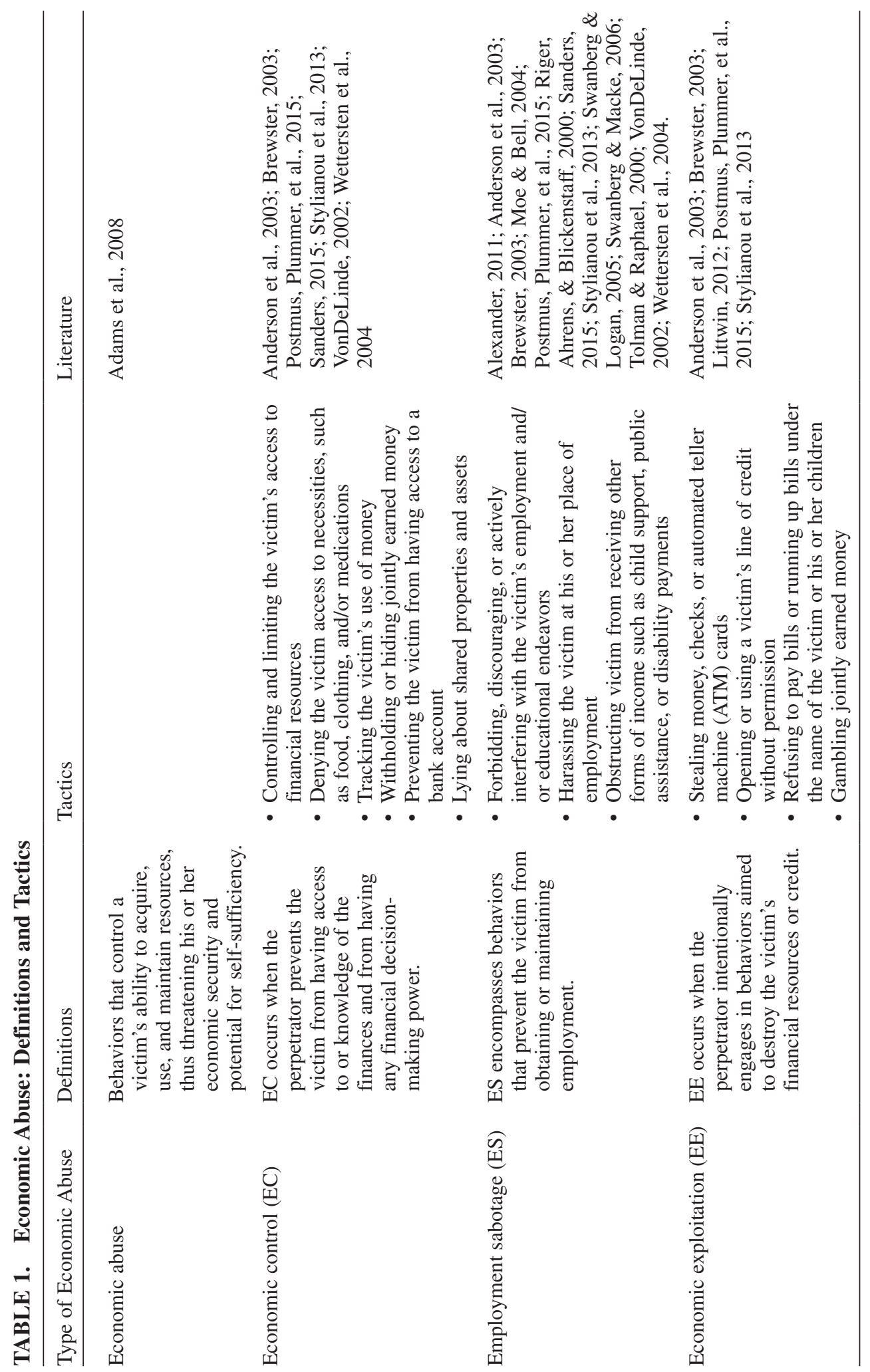


Additional studies have also recognized on-the-job harassment, which includes incidents of the perpetrator physically appearing at the workplace or making repeated telephone calls to the victim or to the victim's coworkers and supervisors (Riger et al., 2000; Swanberg \& Logan, 2005; Swanberg \& Macke, 2006; Wettersten et al., 2004). For many victims, experiences of employment sabotage cause missed days of work, loss in pay, or the loss of employment (Tolman \& Wang, 2005; Wettersten et al., 2004). Research has also found that perpetrators interfere with their partners' ability to attend educational opportunities and obstruct their partners from receiving other forms of income such as child support, public assistance, or disability payments (Anderson et al., 2003; Brewster, 2003; Moe \& Bell, 2004).

Economic exploitation occurs when a perpetrator intentionally engages in behaviors aimed to destroy the victim's financial resources or credit (Postmus, Plummer, et al., 2015). As consumer lending has increased, perpetrators increasingly use debt as a means of gaining power and control over their partners (Littwin, 2012). This can occur when a perpetrator steals money, checks, or automated teller machine (ATM) cards; opens or uses a victim's line of credit without permission; refuses to pay the mortgage, rent, or other utility payments; runs up bills under the name of the victim or of his or her children; or gambles jointly earned money (Anderson et al., 2003). A perpetrator may also steal or damage the victim's possessions to exploit the victim (Brewster, 2003). One study, conducted by Anderson and colleagues (2003), found that among a sample of 485 women seeking services from a domestic violence advocacy program, $38 \%$ reported their partners stole money from them.

In sum, research has documented a range of economically abusive behaviors that perpetrators use to threaten their partners' economic stability. These economically abusive behaviors fall into three categories: economic control, employment sabotage, and economic exploitation (Postmus, Plummer, et al., 2015; Stylianou et al., 2013). Although the literature has identified a variety of economic abuse tactics, historically, scholars have blurred together measures of economic abuse with other forms of nonphysical abuse. Yet, it is often forms of nonphysical abuse that victims identify as the most devastating forms of abuse, beyond the effects of physical violence (Outlaw, 2009). Identifying and measuring economic abuse is critical to understand the extent and impact of economic abuse on victims of IPV.

\section{MEASURES OF ECONOMIC ABUSE}

Historically, economic abuse has most often been included within the definition of psychological abuse (Shepard \& Campbell, 1992; Tolman, 1989, 1999). Only recently have scholars begun to identify economic abuse as its own unique form of abuse (Adams et al., 2008; Riger et al., 2000; Stylianou et al., 2013; Weaver, Sanders, Campbell, \& Schnabel, 2009). Most of what we know about economic abuse is derived from one or two questions included in larger measures of IPV that focus on physical and/or psychological abuse tactics. For example, the National Violence Against Women Survey (NVAWS; Tjaden \& Thoennes, 1998), a nationally representative survey drawn by random-digit dialing from households in the United States, measured economic abuse experiences with one dichotomous question. The item asked if the respondent's "current partner prevents him/her from knowing about or having access to family income, even when (she/he) asks." The results indicated that economic abuse was a rare phenomenon, occurring less 
frequently than physical abuse experiences (Outlaw, 2009). According to the results, women reported higher rates of economic abuse experiences than men and the risk of experiencing physical abuse was 4.68 times higher among those who experienced economic abuse compared to those who did not experience economic abuse (Outlaw, 2009). Unfortunately, the NVAWS only used one question focused on economic control, which limited the results. Including a broader range of items measuring economic control, employment sabotage, and economic exploitation is needed to assess economic abuse experiences among IPV survivors.

To develop a more expansive measure of economic abuse experiences, scholars have begun to develop scales and subscales of economic abuse (Adams et al., 2008; Lehmann, Simmons, \& Pillai, 2012; Postmus, Plummer, et al., 2015; Weaver et al., 2009). The Domestic Violence-Related Financial Issues Scale (DV-FI; Weaver et al., 2009) was the first scale to incorporate a subscale measuring economic abuse experiences. The DV-FI was tested among a sample of 113 females who were primarily African American, single, impoverished victims of IPV seeking emergency shelter services. The DV-FI was developed to be a comprehensive assessment of the unique financial issues victims of IPV face. The DV-FI included one subscale measuring economic abuse that contained five items. Although the DV-FI expanded the definition of economic abuse when compared to previous one item measures, it is limited to only five items that primarily focus on credit card debt and credit rating. Although these are important items in assessing for economic exploitation, they are narrow in scope and only focus on victims of IPV who are engaged in the formal credit system. The DV-FI does not capture economic exploitation that occurs among victims of IPV that use cash-only finances. The two items focusing on economic control and employment sabotage ("My partner prevented me from having access to money" and "My partner prevented me from obtaining necessary skills or education to obtain adequate employment") are narrowly defined and miss the nuances of the different types of economic abuse strategies used by abusers. Using a measure that fully assesses all three forms of economic abuse applicable to victims of IPV using formal economic services and/or cash-only finances would allow for a more comprehensive measure of economic abuse.

Another subscale created to measure economic abuse is found in the Checklist of Controlling Behaviors (CCB; Lehmann et al., 2012). The CCB is an 84-item domestic violence assessment instrument that is used to address multiple levels of violence and coercive control in IPV relationships. The CCB was validated among a sample of 517 shelter residents in a northern Texas community. Participants ranged from 16 to 68 years of age with $40.3 \%$ identifying as Anglo, 24.8\% identifying as African American, 31.9\% identifying as Hispanic, and 3\% identifying as Other. The CCB includes a subscale of economic abuse with seven items that focus almost exclusively on economic control including items such as "did not allow me equal access to the family money" and "threatened to withhold money from me." Although these seven items focus on capturing experiences of economic control within IPV relationships, there are no items that focus on employment sabotage or economic exploitation. Similar to the DV-FI, the subscale of economic abuse in the CCB accounts for experiences of economic abuse but does not fully measure the array of experiences a victim of economic abuse may experience.

Adams and colleagues (2008) developed the first full scale measuring economic abuse experiences, the Scale of Economic Abuse (SEA). The SEA was constructed from several sources including the existing anecdotal and empirical research as well as from interviews with advocates and IPV victims. Several economic abuse concepts emerged including 
(a) preventing victims' resource acquisition, (b) preventing victims' resource use, and

(c) exploiting victims' resources. These concepts provided the foundation for the initial 120 -item scale. The authors tested this scale with 103 victims receiving services from domestic violence organizations. The study participants' ages ranged from 19 to 60 years with $71 \%$ having children living in their household. Half $(50 \%)$ of the participants were White, $40 \%$ were African American, and $10 \%$ were Other. More than three quarters (78\%) of the participants reported a yearly income lower than $\$ 15,000$, and $10 \%$ were living with the abusive partner at the time of the study. Their analyses resulted in a final SEA of 28 items with two subscales including Economic Exploitation (11 items) and Economic Control (17 items). The total SEA had a reliability coefficient of .93, and the two subscales demonstrated strong internal consistency with alpha coefficients ranging from .91 (Economic Control) to .98 (Economic Exploitation; Adams et al., 2008). The SEA was positively correlated with a modified version of the Conflict Tactics Scale focused on physical abuse experiences (Straus, 1979; as modified by Sullivan, Tan, Basta, Rumptz, \& Davidson, 1992) and the Psychological Maltreatment of Women Inventory (PMWI; Tolman, 1999) indicating that higher levels of economic abuse were significantly related to higher levels of physical and psychological abuse.

The second full scale measuring economic abuse experiences, the Scale of Economic Abuse-Revised (SEA-R; Postmus, Plummer, et al., 2015), is a revised shortened version of the SEA developed to use with victims in research or practice settings. Postmus, Plummer, and colleagues (2015) tested the full SEA on a sample of 120 female victims of abuse receiving services from domestic violence organizations. The mean age for participants was 39 years, with 55\% White, 20\% African American, 18\% Latina/Hispanic, and almost $8 \%$ identifying as Other. Almost half of the participants (49\%) reported a yearly income of less than $\$ 10,000$. Using exploratory factor analysis, the SEA was reduced to 12 items with three subscales including economic control (five items; "Keep financial information from you"), employment sabotage (four items; "Threaten you to make you leave work"), and economic exploitation (three items; "Pay bills late or not pay bills that were in your name or both of your names"). The total SEA-12 had a reliability coefficient of .89, and the Economic Control, Employment Sabotage, and Economic Exploitation subscales demonstrated strong internal consistency with alpha coefficients of .87, .86, and .89 , respectively. The results found that the SEA-12 was positively correlated with the Abusive Behavior Inventory (Shepard \& Campbell, 1992) indicating that higher levels of economic abuse experiences were significantly related to higher levels of physical and psychological abuse experiences.

\section{ECONOMIC ABUSE AS A UNIQUE FORM OF ABUSE}

Although the SEA and the SEA-R (Adams et al., 2008; Postmus, Plummer, et al., 2015) contributed to the literature by expanding measures of economic abuse among victims of IPV, a gap in the literature still existed as to whether economic abuse was a unique form of abuse or a subset of psychological abuse experiences. Stylianou and colleagues (2013) used confirmatory factor analyses to provide evidence that economic abuse was a correlated yet distinct construct from other forms of abuse including physical, psychological, and sexual abuse experiences. The sample in their study consisted of 457 female victims of IPV receiving services from domestic violence organizations. The mean age of the participants was 36 years, with 54\% Latina/Hispanic, 20\% Black, non-Hispanic, 
$18 \%$ White, non-Hispanic, and $8 \%$ Other. Almost half (48\%) reported an annual income of less than $\$ 10,000$. Four models were evaluated including (a) a two-factor model representing psychological abuse and physical violence (with economic abuse included in the psychological abuse indicators and sexual violence included in physical violence indicators); (b) a three-factor model encompassing psychological abuse, physical violence, and sexual violence (with economic abuse included in the psychological indicators); (c) a four-factor model representing psychological abuse, physical violence, sexual violence, and economic abuse; and (d) a six-factor model including psychological abuse, physical violence, sexual violence, economic control, employment sabotage, and economic exploitation. The results found that the final six-factor model including psychological abuse, physical violence, sexual violence, economic control, employment sabotage, and economic exploitation was the best fit to the data supporting the hypothesis that the three forms of economic abuse are distinct constructs from other forms of abuse (Stylianou et al., 2013).

In addition, the paper examined the correlations between the six forms of abuse and found that the three forms of economic abuse were moderately correlated with psychological abuse, physical violence, and sexual violence with correlations ranging from .33 to .68. This finding demonstrated that increased experiences of economic abuse were significantly related to increased experiences of physical, psychological, and sexual abuse experiences (Stylianou et al., 2013). Economic abuse and other forms of abuse, including psychological abuse, physical violence, and sexual violence, often co-occur in abusive relationships (Adams et al., 2008; Postmus, 2011). However, the early literature on economic abuse suggests that economic abuse remains a separate unique construct from other forms of abuse, and in particular, from psychological abuse (Adams et al., 2008; Stylianou et al., 2013).

Two critical dynamics of economic abuse need to be considered in understanding the differences between economic abuse and other forms of abuse. The first dynamic, as mentioned by Stylianou and colleagues (2013), is the spatial component to abusive behaviors. The closer the proximity between the perpetrator and the victim, the higher the number of abusive tactics the perpetrator can use. In order for the perpetrator to engage in physically or sexually violent behaviors, the victim and the perpetrator must be in close proximity. Yet, a perpetrator may engage in psychologically abusive behaviors from anywhere in the world. In order for the perpetrator to engage in psychologically abusive behaviors, the perpetrator must have communication with the victim or with close friends and family members of the victim. In contrast, with a few pieces of identifying information, a perpetrator can engage in economically abusive behaviors without having any contact, communication, or spatial proximity with the victim. Perpetrators of IPV can engage in economically abusive behaviors even when they are unable to engage in physical, sexual, or psychological abuse. Therefore, victims may experience difficulty in ending economic abuse compared to other forms of abuse, and economic abuse experiences may continue even when other forms of abuse have terminated.

The second dynamic that differentiates economic abuse from other forms of abuse is the specific focus of engaging in behaviors that target the financial security of the victim with the goal to create economic dependency on the perpetrator (Adams et al., 2008; Miller, 1995). This differs from emotional abuse, which intends to undermine the victim's sense of value and self-worth; psychological abuse, which degrades the victim's sense of logic and reasoning; and social abuse, which focuses on isolating the victim (Miller, 1995). According to Adams et al. (2008), economic abuse aims to control the victim's ability 
to acquire, use, and maintain economic resources. The focus on controlling and/or destroying the victim's economic resources can have a range of cascading impacts including preventing a victim from leaving an abusive relationship because of economic dependency; preventing the victim from gaining and/or maintaining economic opportunities; impacting the victim's ability to financially care for his or her children; and destroying the victim's economic foundation, such as his or her credit score, which then negatively impacts the victim's future financial opportunities (Littwin, 2012; Postmus, 2011; Swanberg \& Logan, 2005). Therefore, economic abuse can create both short- and long-term impacts above and beyond the impact of psychological, physical, and sexual abuse on victims of IPV (Huang, Postmus, Vikse, \& Wang, 2013; Nancarrow, Lockie, \& Sharma, 2009; Postmus, Huang, \& Stylianou, 2012). Given the uniqueness of economic abuse and the impact economic abuse has on the longer term financial capabilities of IPV victims, it is critical that the field of victim services intentionally focus on better understanding the nature and consequences of economic abuse.

\section{IMPACT OF ECONOMIC ABUSE}

One of the greatest impacts of economic abuse is that it creates economic dependency on the perpetrator. Studies have consistently demonstrated that economic dependence is the primary obstacle victims face in attempting to leave abusive relationships (Adams, 2011; Barnett, 2000; Fawole, 2008; Kim \& Gray, 2008). Economic abuse, and in particular employment sabotage, affects the victim's ability to gain and maintain stable employment. Victims of employment sabotage report having difficulty concentrating at work and performing on the job (Banyard, Potter, \& Turner, 2011; Logan, Shannon, Cole, \& Swanberg, 2007; Ridley et al., 2005; Swanberg \& Logan, 2005; Swanberg, Logan, \& Macke, 2005; Swanberg \& Macke, 2006; Wathen, MacGregor, \& MacQuarrie, 2015; Wettersten et al. 2004). Research has found that victims of IPV report significant absenteeism rates (LeBlanc, Barling, \& Turner, 2014; Swanberg et al., 2005; Swanberg \& Macke, 2006), reduced annual work hours (Tolman \& Wang, 2005), and increased tardiness rates (Swanberg \& Logan, 2005; Swanberg et al., 2005; Swanberg \& Macke, 2006). In addition, IPV is associated with job loss, unemployment, and employment instability (Adams, Bybee, Tolman, Sullivan, \& Kennedy; 2013; Borchers, Lee, Martsolf, \& Maler, 2016; Staggs, Long, Mason, Krishnan, \& Riger, 2007; Swanberg \& Logan, 2005). Research documents the detrimental impact of IPV in the short-term and the impact past IPV experiences have on sustained effects on employment stability over time (Adams et al., 2013; Crowne et al., 2011; Lindhorst, Oxford, \& Gillmore, 2007).

Economic abuse also affects the victim's ability to gain economic self-sufficiency and financial resources. Postmus, Plummer, McMahon, Murshid, \& Kim (2012) examined the impact of economic abuse experiences among 120 female victims of IPV receiving services from domestic violence organizations. The ages of the participants ranged from 18 to 73 years with more than half of the participants identifying as White (55\%), 20\% as African American, $18 \%$ as Latina/Hispanic, and almost $8 \%$ as Other. Almost half of the participants (49\%) reported an annual income of less than $\$ 10,000$. The results found that economic abuse, while controlling for demographic characteristics, was a significant predicator of economic self-sufficiency, defined as the ability to accomplish financially related tasks. Similarly, a study conducted by Schrag (2015) examined economic abuse within a sample of 3,282 women with children interviewed in Waves 4 and 5 of the Fragile 
Families and Child Wellbeing Study, a nationally representative sample of births in hospitals in cities over 200,000 (Princeton University, 2011). The study found that mothers who experienced economic abuse were 1.3 times more likely to experience material hardship, defined as facing shortfalls in meeting basic needs such as food, housing, and medical care, than mothers who did not experience economic abuse. Finally, Adams, Beeble, and Gregory (2015) examined the relationship between economic abuse and financial resources, defined as the respondent's perception of having enough money for necessities, among a sample of 93 women with abusive partners over a period of 4 months. The study participants' ages ranged from 19 to 60 years, with $71 \%$ having children living in their household. Half (50\%) of the participants were White, $40 \%$ were African American, and $10 \%$ identified as Other. More than three quarters (78\%) of the participants reported an annual income of less than $\$ 15,000$, and $10 \%$ were living with the abusive partner at the baseline interview. The findings indicated that after controlling for physical violence and psychological abuse experiences, baseline economic abuse was significantly related to baseline financial resources, and within-women change in economic abuse significantly predicted change in financial resources over time.

Economic abuse also affects the victim's mental health and psychological well-being. Postmus, Huang, and colleagues (2012) used the Fragile Families and Child Wellbeing Study (Princeton University, 2011), a nationally representative sample of births in hospitals in cities over 200,000, to conduct a longitudinal analysis on the impact of psychological, physical, and economic abuse on mothers' levels of depression. The sample consisted of 2,305 mothers with a mean age of 25.8 years with more than $40 \%$ of mothers identifying as non-Hispanic Black (42\%), one-quarter Hispanic (28\%) and non-Hispanic White (27\%), and $4 \%$ as Other. When controlling for demographic variables, mothers who experienced economic abuse were 1.9 times more likely to exhibit depression than mothers who had not experienced economic abuse. Furthermore, when testing for level and changes in abuse experiences over time, only economic abuse (not physical or psychological abuse) significantly predicted maternal depression.

Similar studies have linked economic abuse experiences to mental health symptomatology. Nancarrow et al. (2009) found that among 532 women living in Central Queensland's mining region, economic abuse experiences was the highest risk factor (when compared to psychological, sociopsychological, and nonphysical forms of abuse) for depression. Hamdan-Mansour, Arabiat, Sato, Obaid, \& Imoto (2011) studied 915 women in the southern region of Jordan. The participants had a mean age of 34.6 years, almost all (85\%) were married, and almost half (45\%) had less than a secondary level of education. The study found that economic abuse experiences were significantly related to decreases in psychological well-being, self-acceptance, and environmental mastery. Finally, Antai, Oke, Braithwaite, \& Lopez (2014) used the 2008 Philippines National Demographic and Health Surveys, a nationally representative household sample survey conducted with women aged 15-49 years and found that among a sample of 9,316 women, economic abuse experiences predicted psychological distress and suicide attempts.

Additional research has established relationships between economic abuse experiences and family formations, parenting practices, children's behaviors, and youth outcomes. A study conducted by Postmus, Huang, and colleagues (2012) used the Fragile Families and Child Wellbeing Study (Princeton University, 2011), a nationally representative sample of births in hospitals in cities over 200,000, to examine the long-term impact of IPV on parenting. Findings indicated that economic abuse at Year 1 had significant effects on the likelihood of mothers spanking their children at Year 5. Similarly, Huang et al. (2013) 
used the same dataset to examine the occurrence of and changes in economic abuse over time and how economic abuse influenced union formation among mothers. The results demonstrated that the prevalence of economic abuse increased over time and both the occurrence and the increase in economic abuse were significantly and negatively associated with the likelihood of stable union formations such as marriage and cohabitation.

Initial research has also demonstrated the impact of exposure to economic abuse on children. Huang, Vikse, Lu, and Yi (2015) examined the effects of exposure to IPV in early childhood (as measured by their mothers' experiences with physical violence and economic abuse) on children's delinquency at age 9 years based on children's selfreport of their own history of behaviors. Huang and colleagues used the Fragile Families Dataset (Princeton University, 2011), a nationally representative sample of births in hospitals in cities over 200,000. The results indicated that with respect to the two types of IPV (physical violence and economic abuse), only the presence of economic abuse was statistically shown to be significantly associated with child delinquency at age 9 years. These findings highlight the persistent, long-term effects of children's early exposure to economic abuse.

Similarly, Schrag, Edmond, Tlapek, and Auslander (2016) examined the impact of witnessing economic abuse tactics among female youth involved in the child welfare system. The sample consisted of 105 adolescent girls, aged 12-19 years, with just lower than half $(41 \%)$ of the participants identifying as White and 59\% identifying as youth of color. Nearly half of the sample reported witnessing moderate or high levels of exposure to economic abuse. Increased exposure to economic abuse was significantly related to increased rates of depression and posttraumatic stress disorder symptomatology and decreased rates of financial self-efficacy, defined as the belief in one's ability to succeed at a given financial task in the future (Schrag et al., 2016).

In sum, economic abuse experiences have been found to be associated with a range of negative outcomes among victims including difficulty gaining or maintaining employment (Swanberg \& Logan, 2005), difficulty establishing economic self-sufficiency (Postmus, Plummer, et al., 2012; Schrag, 2015), and increased rates of depressive symptoms and decreased rates of psychological well-being (Antai et al., 2014; Hamdan-Mansour et al., 2011; Nancarrow et al., 2009; Postmus, Huang, et al., 2012). In addition, economic abuse experiences impact family outcomes including decreased stable family formations, parenting practices, children's behaviors, and youth outcomes (Huang et al., 2013; Huang et al., 2015; Postmus, Huang, et al., 2012; Schrag et al., 2016). Not only does this early literature provide evidence to both the short- and long-term impacts of economic abuse among victims of IPV and their children, but it also begins to document the impact of economic abuse above and beyond the impact of other forms of IPV.

\section{INTERVENTIONS}

As the field of IPV increasingly recognizes the impact of economic abuse on victims, advocates have focused their efforts to make economic issues a primary component of domestic violence interventions (Christy-McMullin, 2003; Sanders \& Schnabel, 2006). Numerous economic empowerment programs have been developed that focus on both increasing basic financial knowledge and skills and empowering victims through increasing victims' sense of confidence about their ability to manage their own finances and to develop safety plans for their financial future (Sanders, Weaver, \& Schnabel, 2007). 
The most studied economic empowerment program for victims of IPV are financial literacy programs. Financial literacy programs for IPV survivors incorporate traditional financial literacy topics along with safety-related topics specifically for victims of IPV as well as introducing of the concept of economic abuse. To date, there are two models that have been found to be effective financial literacy models among victims of IPV: the Redevelopment Opportunities for Women's Economic Action Program (REAP) funded by the National Endowment for Financial Education and the Allstate Foundation's Moving Ahead through Financial Management curriculum.

REAP emphasizes the intersection of poverty, oppression, and violence while providing financial information to victims of IPV (Sanders et al., 2007). The curriculum includes both group and individual activities delivered over the course of a 12-hour group format broken down into four classes. The curriculum covers the following topic areas: money and power, developing a cost-of-living plan, building and repairing credit, and banking and investing (VonDeLinde, 2005). The aim of the curriculum is to increase access to knowledge of financial information and resources and increase victims' confidence in managing and coping with financial problems (Sanders et al., 2007). The REAP program was evaluated using a quasi-experimental design with 117 victims of IPV receiving services at domestic violence organizations. The sample consisted primarily of women between the ages of 18 and 50 years (98.5\%), almost three quarters identified as African American (73\%), almost one quarter as White $(21 \%)$, and $6 \%$ as Biracial or Latina. Almost half $(43 \%)$ of the participants were making less than $\$ 250$ a month and one third were employed at least part-time or in school (35\%). The length of time with the abusive partner in months ranged from 1 to 297 with a mean of 69 months. The results indicated that victims receiving the REAP curriculum made limited gains in financial literacy and significant improvements in financial self-efficacy compared to victims who received services as usual (Sanders et al., 2007). Although the average participant made moderate gains in financial literacy over time, the differences in the change of financial literacy scores between the experimental and control groups were not significant when the length of time the victim spent with the abuser was included in the model. However, the length of time the victim spent with the abuser was found to be a significant predictor of the change in financial knowledge score. That is, the longer the victim was with the perpetrator, the more his or her financial literacy score improved over time. Yet when examining the impact of the curriculum on change in financial self-efficacy, even when controlling for the length of the relationship, participants in the experimental group had a significantly greater change in financial selfefficacy than participants in the control group. This finding highlights the importance of providing financial literacy programs, particularly to victims who have been in long-term abusive relationships, to increase financial literacy and even more importantly to increase financial self-efficacy.

A similar evaluation was conducted examining a combined financial literacy and individual development accounts (IDAs) intervention using REAP's curriculum and a women's IDA program (Sanders, 2014). The IDAs could be used to purchase or repair a home, acquire career-enhancing education, purchase an automobile, start or support a small business or microenterprise, or for retirement. Women were also able to access their own funds (but not the matching funds) for emergency needs. The sample consisted of 125 female victims of IPV with $46 \%$ of participants identifying as Black, $42 \%$ as White, and $12 \%$ as Other. The average age of the sample was 37 years, and almost three quarters had at least some college education (70\%). The majority of the participants were single (42\%), divorced (35\%), or separated (11\%), and almost all of 
the women (91\%) lived at or below the $150 \%$ of the poverty line. Among those who participated in the IDA matched savings program, two thirds reached their savings goal, and 76\% made at least one matched withdrawal (Sanders, 2014). The average participant saved $\$ 1,310$, which increased to $\$ 3,014$ with the matched funding (Sanders, 2014). This research provides early evidence that when institutional support and access to resources are available, IPV victims can successfully save and purchase financial assets.

A similar financial literacy curriculum, created by the Allstate Foundation in collaboration with the National Network to End Domestic Violence, the Moving Ahead Through Financial Management curriculum, was evaluated and found to have a significant impact on victims of IPV. The Allstate Foundation model contains five modules, including (a) understanding financial abuse, (b) learning financial fundamentals, (c) mastering credit basics, (d) building financial foundations, and (e) creating budget strategies. There are three objectives of the program. The first overall objective is for participants to gain basic financial knowledge around budgeting, credit, and financial management. The second objective is for participants to understand basic financial processes including loan applications, filing for bankruptcy, running a credit score, and filling out the accompanying financial paperwork. The final objective includes information about gaining financial safety including disentangling joint financial accounts, repairing credit damaged by an abuser, locating safety and financial resources, and forming economic safety plans and strategies. The program allows for flexibility in the delivery of the curriculum, and staff are encouraged to use both individual and group sessions (Postmus, Hetling, \& Hoge, 2015).

The Allstate Foundation model was evaluated through a longitudinal randomized control trial with 300 female victims of IPV receiving services from domestic violence organizations. The mean age of the participants was 36 years, with 54\% Latina/Hispanic, $20 \%$ Black, non-Hispanic, 18\% White, non-Hispanic, and 8\% Other. Almost half (48\%) reported an annual income of less than $\$ 10,000$. Approximately 1 in $5(19 \%)$ of the participants reported living in the abusive relationship, whereas $81 \%$ reported having left the abusive relationship. Participants qualified to participate in the research study if they had experienced IPV over the past year, whether or not they remained with or were separated from the abusive partner. Over the 14-month period, participants who received the Allstate Foundation financial management curriculum had a significant increase in selfreported financial knowledge, financial intentions, and financial behaviors and a decrease in financial strain when compared to participants who received services as usual (Hetling, Postmus, \& Kaltz, 2015; Postmus, Hetling, et al., 2015).

Historically, domestic violence interventions have focused heavily on crisis intervention, advocacy, and individual counseling services. When the economic needs of victims are addressed, it is often with a focus on short-term needs (Christy-McMullin, 2002). However, as demonstrated by the research (Postmus, Hetling, et al., 2015; Sanders et al., 2007). Financial literacy programs need to be considered a critical intervention for victims of IPV because financial literacy programs have the potential to increase victims' economic self-efficacy, financial literacy, and financial behaviors. In addition, financial literacy has been found to be associated with significant positive outcomes among victims of IPV. Postmus, Plummer, McMahon, and Zurlo (2013) found that among female victims of IPV, higher financial literacy was significantly associated with higher levels of economic empowerment, conceptualized as the knowledge, skills, and confidence to address one's own financial well-being. 


\section{IMPLICATIONS}

The learning from the field of economic abuse has critical research, practice, and police implications.

\section{Research}

Although two measures of economic abuse have been validated in the literature (SEA, Adams et al., 2008; SEA-R, Postmus, Plummer, et al., 2015), further validation of the scales among more diverse populations, including victims residing in rural areas; Native American and Asian victims; male victims; lesbian, gay, bisexual, transgender, and queer/questioning (LGBTQ)-identified victims; victims with disabilities; immigrant victims; and victims of diverse socioeconomic backgrounds, is needed. Additional research is needed to understand the dynamics of economic abuse across multiple family formations including heterosexual and LGBTQ relationships; married, dating, and cohabitating relationships; and families with and without children. Furthermore, although studies among victims of IPV have found high rates of economic abuse experiences among victims, no study has examined the prevalence of economic abuse experiences in the general public using a comprehensive measure of economic abuse.

Research is also needed to explore the relationships between economic abuse and outcome variables for victims of IPV and their children. Studies need to examine at what point economic abuse experiences lead to negative outcomes, the relationships between the different outcome variables, potential mediating and moderating variables, and the impact of interactions of multiple forms of abuse on the outcome variables. Furthermore, research is needed to understand characteristics of individuals who perpetrate economic abuse against their partners and to identify risk and protective factors around economic abuse behaviors.

Last, although initial research has found financial literacy interventions, such as REAP (Sanders et al., 2007) and the Allstate Foundation's curriculum (Postmus, Hetling, et al., 2015), to be effective interventions among victims of IPV, further research is needed to understand the effectiveness of the interventions in supporting victims after leaving abusive relationships and in protecting victims remaining in abusive relationships. Research is needed to test the effectiveness of these interventions among more diverse populations.

\section{Practice}

Advocates and domestic violence organizations need to make economic issues a primary component of domestic violence interventions (Correia, 2000; VonDeLinde, 2002). Organizations need to commit to focusing on increasing the financial empowerment of clients not just through providing referrals but also by offering extensive economic services that address both the short- and long-term needs of IPV victims and their children. For many domestic violence organizations, this means integrating economic empowerment into their vision of key service provision priorities, committing resources to train staff and implement economic programming, and advocating for funding and policies that improve the financial conditions for victims of IPV. It also means conceptualizing economic empowerment programming as a critical service to support victims remaining in abusive relationships. As research has demonstrated, the primary reason victims remain in abusive relationships is because of financial dependence on the abuser (Adams, 2011; Barnett, 2000; Fawole, 2008; Kim \& Gray, 2008). Therefore, economic empowerment services are critical in supporting 
victims in abusive relationships to gain the financial independence needed to leave the relationship. Furthermore, economic empowerment services may have the potential to decrease future abuse by supporting victims in gaining financial independence within the relationship and thereby shifting the financial power dynamics of the relationship.

Advocates need training on how to explore economic abuse with IPV victims. Unlike physical abuse, many economic abuse behaviors are covert behaviors that may not be readily apparent to either the victim or the advocate as a form of abuse. Advocates need to understand the dynamics that occur in economically abusive relationships and be equipped with tools to assess for economic abuse experiences with victims of IPV. Advocates need to be prepared to codevelop safety plans to address the range of financial risks a victim may face. Identifying ways to increase financial safety, access financial resources and assets, review and improve credit, and gain or maintain employment and/or educational opportunities can support the victim in increasing his or her financial safety and independence.

Domestic violence organizations need to focus on providing financial literacy services and on increasing collaborations with community agencies providing economic empowerment services (VonDeLinde, 2002). Economic services provided within domestic violence organizations must be developed, implemented, and tailored to the unique needs of victims of IPV (Sanders et al., 2007). Incorporating concepts of financial safety planning and economic abuse into traditional financial literacy curriculum and services will provide victims of IPV with a comprehensive approach to improving their economic empowerment.

\section{Policy}

State and federal policies designed to prosecute offenders and support victims of IPV need to be expanded to acknowledge and prohibit economic abuse. Currently in the United States, domestic violence criminal offenses are primarily enforced through local and state governments and each state varies in their domestic violence provisions. Generally, an act of domestic violence is committed when a criminal offense such as (but not limited to) disorderly conduct, harassment, aggravated harassment, sexual abuse, stalking, criminal obstruction of breathing or blood circulation, strangulation, or assault occur between current or former spouses, parent and child, and members of the same family or household. However, each state varies in its criminal code and in its definition of domestic violence. Although physical abuse and stalking behaviors are often simple to classify under state criminal code and therefore enforceable by the criminal justice system, many components of psychological abuse and economic abuse do not qualify as a crime under criminal code. Among economic abuse, more overt forms of economic abuse such as opening a line of credit under the victim's name without permission can be prosecuted under criminal law, whereas more covert forms of abuse such as controlling the finances and limiting access to shared finances rarely meet state standards to be considered a criminal offense.

To address this gap in the criminal code in the United Kingdom, The Serious Crime Act of 2015 created a new crime entitled "Controlling or coercive behaviour in an intimate or family relationship" (Section 76). The law specifies that

A person (A) commits an offense if

(a) repeatedly or continuously engages in behaviour towards another person (B) that is controlling or coercive,

(b) at the time of the behaviour, A and B are personally connected,

(c) the behaviour has a serious effect on $\mathrm{B}$, and

(d) A knows or ought to know that the behaviour will have a serious effect on B. 
This new offense closed a gap in the law around patterns of controlling or coercive behavior among intimate partners or family members. The offense carries a maximum sentence of 5 years imprisonment, a fine, or both. The government also released a statutory guidance framework for the police and criminal justice agencies involved in the investigations of this new offense (Home Office, 2015). The framework defines a controlling behavior as

a range of acts designed to make a person subordinate and/or dependent by isolating them from sources of support, exploiting their resources and capacities for personal gain, depriving them of the means needed for independence, resistance and escape and regulating their everyday behaviour. (p. 3)

In addition, the framework provides a list of behaviors associated with coercion or control that include behaviors that fall under the concept of economic abuse including depriving the victim of his or her basic needs, preventing the victim from having access to transport or from working, and economic control including control of finances. The United States needs to model policies from the United Kingdom in creating criminal offenses for psychological and economic abuses to further protect and support victims of IPV.

State and federal policies need to provide employment protections to victims of domestic violence and mandate that places of employment develop and implement policies to support employees who are experiencing IPV. Currently, federal equal employment opportunity laws do not prohibit discrimination against job applicants or employees who experience domestic violence. However, many states have enacted laws protecting employment rights for victims of domestic violence. In California, an employer may not discharge or discriminate or retaliate against an employee who is a victim of domestic violence or sexual assault for taking time off to obtain or attempt to obtain a restraining order or any other judicial relief to help ensure his or her health, safety, or welfare or that of his or her child (California Labor Code $\S \S 230,230.1,2006)$. In Illinois, according to the Victim's Economic Security and Safety Act (VESSA; 2003), an employee who is a victim of domestic or sexual violence or has a family or household member who is a victim of such violence may take up to 12 workweeks of unpaid leave to address the violence. This leave may be used to seek medical attention or counseling, obtain services from a victim service organization, participate in safety planning or relocation, or seek legal assistance. In New York, victims of domestic violence are a group protected from employment discrimination (Human Rights Law, N.Y. Exec. L. §§ 292(34), 296-1(a), 2009). In New York City, the Human Rights Law prohibits an employer from refusing to hire, discharging, or discriminating against an individual because the individual is or is perceived to be a victim of domestic violence, sex offenses, or stalking (Unlawful Discriminatory Practices, N.Y. Admin. Code § 8-107.1, 2016).

Although there are no federal equal employment opportunity laws prohibiting discrimination against job applicants or employees who experience domestic violence, there are also no federal laws requiring domestic violence workplace policies (Swanberg, Ojha, \& Macke, 2012). Several states and cities require state agencies to adopt workplace policies on domestic violence, and some jurisdictions have passed laws or established task forces to create model workplace policies for the voluntary adoption by public and private employees. These recommendations often include prohibiting discrimination against employees who are victims of domestic violence, establishing confidential means for reporting domestic violence, providing education and training on domestic violence to all employees, posting resource and referral information in easily accessible and highly 
visible locations, providing adjusted work schedules and/or leave to obtain medical care, counseling or legal assistance, increasing the safety of the workplace, and disciplining and/or discharging employees who threaten or abuse others on work time or outside of the workplace (Legal Momentum, 2009). All federal, state, and local governments should implement laws both protecting victims of domestic violence from employment discrimination and requiring places of employment to implement domestic violence workplace policies to support victims of domestic violence at the workplace.

\section{CONCLUSION}

The field of IPV has made considerable gains in the past decades in increasing our understanding of abusive behaviors and tactics, understanding the impact abuse has on victims and their children, and developing and implementing programming to both prevent IPV and provide support to victims of IPV. As we move forward, the field needs to increase its focus on economic abuse and on developing practices and policies aimed specifically at economic abuse. Research has demonstrated that economic abuse is a unique form of abuse that has both short- and long-term impacts on victims of IPV and their children. Furthermore, early research provides evidence that economic abuse affects victims of IPV above and beyond other forms of abuse including physical violence, psychological abuse, and sexual violence. Although initial research has demonstrated the effectiveness of financial literacy programs implemented among victims of IPV, further program development is needed to develop and test interventions across diverse populations. Finally, researchers, advocates, and policymakers need to focus efforts on providing services and options to victims of IPV experiencing economic abuse.

\section{REFERENCES}

Adams, A. E. (2011, May). Measuring the effects of domestic violence on women's financial wellbeing (CFS Research Brief 2011-5.6). Madison, WI: Center for Financial Security, University of Wisconsin-Madison.

Adams, A. E., Beeble, M. L., \& Gregory, K. A. (2015). Evidence of the construct validity of the Scale of Economic Abuse. Violence and Victims, 30(3), 363-376.

Adams, A. E., Bybee, D., Tolman, R. M., Sullivan, C. M., \& Kennedy, A. C. (2013). Does job stability mediate the relationship between intimate partner violence and mental health among lowincome women? The American Journal of Orthopsychiatry, 83(4), 600-608.

Adams, A. E., Sullivan, C. M., Bybee, D., \& Greeson, M. R. (2008). Development of the Scale of Economic Abuse. Violence Against Women, 14(5), 563-588.

Alexander, P. C. (2011). Childhood maltreatment, intimate partner violence, work interference and women's employment. Journal of Family Violence, 26(4), 255-261.

Anderson, M. A., Gillig, P. M., Sitaker, M., McCloskey, K., Malloy, K., \& Grigsby, N. (2003). "Why doesn't she just leave?": A descriptive study of victim reported impediments to her safety. Journal of Family Violence, 18(3), 151-155.

Antai, D., Oke, A., Braithwaite, P., \& Lopez, G. B. (2014). The effect of economic, physical, and psychological abuse on mental health: A population-based study of women in the Philippines. International Journal of Family Medicine, 2014, 852317.

Banyard, V., Potter, S., \& Turner, H. (2011). The impact of interpersonal violence in adulthood on women's job satisfaction and productivity: The mediating roles of mental and physical health. Psychology of Violence, 1(1), 16-28. 
Barnett, O. W. (2000). Why battered women do not leave, part 1: External inhibiting factors within society. Trauma, Violence, \& Abuse, 1(4), 343-372.

Borchers, A., Lee, R. C., Martsolf, D. S., \& Maler, J. (2016). Employment maintenance and intimate partner violence. Workplace Health \& Safety, 64(10), 469-478.

Breiding, M. J., Chen, J., \& Black, M. C. (2014). Intimate partner violence in the United States-2010. Atlanta, GA: National Center for Injury Prevention and Control, Centers for Disease Control and Prevention.

Brewster, M. P. (2003). Power and control dynamics in prestalking and stalking situations. Journal of Family Violence, 18(4), 207-217.

California Labor Code, $\S \S 230,230.1$ (2006). Retrieved from http://leginfo.legislature.ca.gov/faces/ codes_displaySection.xhtml?lawCode $=$ LAB\&sectionNum $=230.1$

Centers for Disease Control and Prevention. (2016). Intimate partner violence: Definitions. Retrieved from http://www.cdc.gov/violenceprevention/intimatepartnerviolence/definitions/html

Christy-McMullin, K. (2002). Designing policies that address the relationship between woman abuse and economic resources. Journal of Sociology and Social Welfare, 29, 109-124.

Christy-McMullin, K. (2003). Asset-building policies and safety for women: Stretching social work's conceptual framework. The Social Policy Journal, 2(4), 19-37.

Correia, A. (2000). Strategies to expand battered women's economic opportunities (Building Comprehensive Solutions to Domestic Violence Publication No. 9). Linglestown, PA: National Resource Center on Domestic Violence.

Crowne, S. S., Juon, H. S., Ensminger, M., Burrell, L., McFarlane, E., \& Duggan, A. (2011). Concurrent and long-term impact of intimate partner violence on employment stability. Journal of Interpersonal Violence, 26(6), 1282-1304.

Fawole, O. I. (2008). Economic violence to women and girls: Is it receiving the necessary attention? Trauma, Violence, \& Abuse, 9(3), 167-177.

Hamdan-Mansour, A. M., Arabiat, D. H., Sato, T., Obaid, B., \& Imoto, A. (2011). Marital abuse and psychological well-being among women in the southern region of Jordan. Journal of Transcultural Nursing, 22(3), 265-273.

Hetling, A., Postmus, J. L., \& Kaltz, C. (2015). A randomized controlled trial of a financial literacy curriculum for survivors of intimate partner violence. Journal of Family and Economic Issues, $37(4), 672-685$.

Home Office. (2015). Controlling or coercive behaviour in an intimate or family relationship: Statutory guidance framework. London, United Kingdom: The Stationery Office. Retrieved from https://www.gov.uk/government/uploads/system/uploads/attachment_data/file/482528/ Controlling_or_coercive_behaviour_-_statutory_guidance.pdf

Huang, C. C., Postmus, J. L., Vikse, J. H., \& Wang, L. R. (2013). Economic abuse, physical violence, and union formation. Children and Youth Services Review, 35(5), 780-786.

Huang, C. C., Vikse, J. H., Lu, S., \& Yi, S. (2015). Children's exposure to intimate partner violence and early delinquency. Journal of Family Violence, 30(8), 953-965.

Human Rights Law, N.Y. Exec. L. §§ 292(34), 296-1(a) (2009). Retrieved from http://www.nyc.gov/ html/dcas/downloads/pdf/misc/psb_100_13_296.pdf

Kasian, M., \& Painter, S. L. (1992). Frequency and severity of psychological abuse in a dating population. Journal of Interpersonal Violence, 7(3), 350-364.

Kim, J., \& Gray, K. A. (2008). Leave or stay? Battered women's decision after intimate partner violence. Journal of Interpersonal Violence, 23(10), 1465-1482.

LeBlanc, M. M., Barling, J., \& Turner, N. (2014). Intimate partner aggression and women's work outcomes. Journal of Occupational Health Psychology, 19(4), 399-412.

Legal Momentum. (2009). State law guide: Domestic and sexual violence workplace policies. Retrieved from https://www.legalmomentum.org/sites/default/files/reports/domestic-violence-workplace.pdf

Lehmann, P., Simmons, C. A., \& Pillai, V. K. (2012). The validation of the Checklist of Controlling Behaviors (CCB): Assessing coercive control in abusive relationships. Violence Against Women, 18(8), 913-933. 
Lindhorst, T., Oxford, M., \& Gillmore, M. R. (2007). Longitudinal effects of domestic violence on employment and welfare outcomes. Journal of Interpersonal Violence, 22(7), 812-828.

Littwin, A. (2012). Coerced debt: The role of consumer credit in domestic violence. California Law Review, 100, 951-1026.

Logan, T. K., Shannon, L., Cole, J., \& Swanberg, J. (2007). Partner stalking and implications for women's employment. Journal of Interpersonal Violence, 22(3), 268-291.

Miller, M. S. (1995). No visible wounds: Identifying nonphysical abuse of women by their men. New York, NY: Random House.

Moe, A. M., \& Bell, M. P. (2004). Abject economics: The effects of battering and violence on women's work and employability. Violence Against Women, 10(1), 29-55.

Nancarrow, H., Lockie, S., \& Sharma S. (2009). Intimate partner abuse of women in a Central Queensland mining region (Trends and Issues in Crime and Criminal Justice No. 378). Canberra, Australia: Criminology Research Council, Australian Institute of Criminology, Australian Government.

Outlaw, M. (2009). No one type of intimate partner abuse: Exploring physical and non-physical abuse among intimate partners. Journal of Family Violence, 24(4), 263-272.

Postmus, J. L. (2011). Understanding financial literacy with survivors of intimate partner violence (CSF Research Brief 2011-5.2). Retrieved from http://www.cfs.wisc.edu/briefs/Postmus2011_ ResearchBrief.pdf

Postmus, J. L., Hetling, A., \& Hoge, G. L. (2015). Evaluating a financial education curriculum as an intervention to improve financial behaviors and financial well-being of survivors of domestic violence: Results from a longitudinal randomized controlled study. The Journal of Consumer Affairs, 49(1), 250-266.

Postmus, J. L., Huang, C. C., \& Stylianou, A. M. (2012). The impact of physical and economic abuse on maternal mental health and parenting. Children and Youth Services Review, 34(9), 1922-1928.

Postmus, J. L., Plummer, S. B., McMahon, S., Murshid, N. S., \& Kim, M. S. (2012). Understanding economic abuse in the lives of survivors. Journal of Interpersonal Violence, 27(3), 411-430.

Postmus, J. L., Plummer, S. B., McMahon, S., \& Zurlo, K. A. (2013). Financial literacy: Building economic empowerment with survivors of violence. Journal of Family and Economic Issues, 34(3), 275-284.

Postmus, J. L., Plummer, S. B., \& Stylianou, A. M. (2015). Measuring economic abuse in the lives of survivors: Revising the Scale of Economic Abuse. Violence Against Women, 22(6), 692-703.

Princeton University. (2011). Fragile Families and Child Wellbeing Study data alerts. Retrieved from http://www.fragilefamilies.princeton.edu/index.asp

Ridley, E., Rioux, J., Lim, K. C., Mason, D., Houghton, K. F., Luppi, F., \& Melody, T. (2005). Domestic violence survivors at work: How perpetrators impact employment. Augusta, ME: Maine Department of Labor and Family Crisis Services.

Riger, S., Ahrens, C., \& Blickenstaff, A. (2000). Measuring interference with employment and education reported by women with abusive partners: Preliminary data. Violence and Victims, 15(2), 161-172.

Sackett, L. A., \& Saunders, D. G. (1999). The impact of different forms of psychological abuse on battered women. Violence and Victims, 14(1), 105-117.

Sanders, C. K. (2014). Savings for survivors: An individual development account program for survivors of intimate-partner violence. Journal of Social Service Research, 40(3), 297-312.

Sanders, C. K. (2015). Economic abuse in the lives of women abused by an intimate partner: A qualitative study. Violence Against Women, 21(1), 3-29.

Sanders, C. K., \& Schnabel, M. (2006). Organizing for economic empowerment of battered women: Women's savings accounts. Journal of Community Practice, 14(3), 47-68.

Sanders, C. K., Weaver, T. L., \& Schnabel, M. (2007). Economic education for battered women: An evaluation of outcomes. Affilia, 22(3), 240-254.

Schrag, R. J. V. (2015). Economic abuse and later material hardship: Is depression a mediator? Affilia, 30(3), 341-351. 
Schrag, R. J. V., Edmond, T., Tlapek, S. M., \& Auslander, W. (2016). Exposure to economically abusive tactics among adolescent girls in the child welfare system. Child and Adolescent Social Work Journal, 34(2), 127-136.

Serious Crime Act, Chapter 9, § 76 (2015). Retrieved from http://www.legislation.gov.uk/ukpga/ 2015/9/section/76/enacted

Shepard, M. F., \& Campbell, J. A. (1992). The Abusive Behavior Inventory: A measure of psychological and physical abuse. Journal of Interpersonal Violence, 7(3), 291-305.

Staggs, S. L., Long, S. M., Mason, G. E., Krishnan, S., \& Riger, S. (2007). Intimate partner violence, social support, and employment in the post-welfare reform era. Journal of Interpersonal Violence, 22(3), 345-367.

Straus, M. A. (1979). Measuring intrafamily conflict and violence: The Conflict Tactics (CTS) Scale. Journal of Marriage and the Family, 41, 75-88.

Stylianou, A. M., Postmus, J. L., \& McMahon, S. (2013). Measuring abusive behaviors: Is economic abuse a unique form of abuse? Journal of Interpersonal Violence, 28(16), 3186-3204.

Sullivan, C. M., Tan, C., Basta, J., Rumptz, M. H., \& Davidson, W. S., II. (1992). An advocacy intervention program for women with abusive partners: Initial evaluation. American Journal of Community Psychology, 20, 309-332.

Swanberg, J. E., \& Logan, T. K. (2005). Domestic violence and employment: A qualitative study. Journal of Occupational Health Psychology, 10(1), 3-17.

Swanberg, J. E., Logan, T. K., \& Macke, C. (2005). Intimate partner violence, employment, and the workplace: Consequences and future directions. Trauma, Violence, \& Abuse, 6(4), 286-312.

Swanberg, J. E., \& Macke, C. (2006). Intimate partner violence and the workplace: Consequences and disclosure. Affilia, 21(4), 391-406.

Swanberg, J. E., Ojha, M. U., \& Macke, C. (2012). State employment protection statues for victims of domestic violence: Public policy's response to domestic violence as an employment matter. Journal of Interpersonal Violence, 27(3), 587-619.

Tjaden, P., \& Thoennes, N. (1998). Prevalence, incidence, and consequences of violence against women: Findings from the national violence against women survey. Washington, DC: National Institute of Justice.

Tolman, R. M. (1989). The development of a measure of psychological maltreatment of women by their male partners. Violence and Victims, 4(3), 159-177.

Tolman, R. M. (1999). The validation of the Psychological Maltreatment of Women Inventory. Violence and Victims, 14(1), 25-37.

Tolman, R. M., \& Raphael, J. (2000). A review of research on welfare and domestic violence. Journal of Social Issues, 56(4), 655-682.

Tolman, R. M., \& Wang, H. C. (2005). Domestic violence and women's employment: Fixed effects models of three waves of women's employment study data. American Journal of Community Psychology, 36(1-2), 147-158.

Unlawful Discriminatory Practices, N.Y. Admin. Code § 8-107.1 (2016). Retrieved from http://www1 .nyc.gov/assets/ocdv/downloads/pdf/New\%20York\%20City\%20Human\%20Rights\%20Law.pdf

Victim's Economic Security and Safety Act, 820 ILCS 180 (2003). Retrieved from http://www.ilga .gov/legislation/ilcs/ilcs3 .asp? ActID=2502\&ChapterID $=68$

VonDeLinde, K. C. (2002). How are domestic violence programs meeting the economic needs of battered women in Iowa? An assessment and recommendations (Building Comprehensive Solutions to Domestic Violence Publication No. 16). Linglestown, PA: National Resource Center on Domestic Violence.

VonDeLinde, K. C. (2005). Economic education programs for battered women: Lessons learned from two settings (Building Comprehensive Solutions to Domestic Violence Publication No. 18). Linglestown, PA: National Resource Center on Domestic Violence.

Wathen, C. N., MacGregor, J. C., \& MacQuarrie, B. J. (2015). The impact of domestic violence in the workplace: Results from a Pan-Canadian survey. Journal of Occupational and Environmental Medicine, 57(7), e65-e71. 
Weaver, T. L., Sanders, C. K., Campbell, C. L., \& Schnabel, M. (2009). Development and preliminary psychometric evaluation of the domestic violence-related financial issues scale (DV-FI). Journal of Interpersonal Violence, 24(4), 569-585.

Wettersten, K. B., Rudolph, S. E., Faul, K., Gallagher, K., Trangsrud, H. B., Adams, K., . . . Terrance, C. (2004). Freedom through self-sufficiency: A qualitative examination of the impact of domestic violence on the working lives of women in shelter. Journal of Counseling Psychology, 51(4), 447-462.

Correspondence regarding this article should be directed to Amanda M. Stylianou, PhD, LCSW, Senior Director, Research and Program Development, Safe Horizon, 2 Lafayette Street, 3rd Floor, New York, NY 10007. E-mail: amanda.stylianou@safehorizon.org 